\title{
Short-term complications of anesthetic technique used in hip fracture surgery in elderly people
}

\author{
Afsaneh Norouzi (1), Fozhan Behrouzibakhsh (2), Alireza Kamali (1), Bijan Yazdi (1), Babak \\ Ghaffari (3) \\ (1) Department of Anesthesiology, Arak University of Medical Sciences, Arak; (2) Arak \\ University of Medical Sciences, Arak; (3) Department of Orthopedics, Arak University of \\ Medical Sciences, Arak, Iran
}

This article is distributed under the terms of the Creative Commons Attribution Noncommercial License (CC BY-NC 4.0) which permits any noncommercial use, distribution, and reproduction in any medium, provided the original author(s) and source are credited.

\begin{abstract}
Postoperative complications of fracture are one of the main problems in older patients with hip fracture. In this study, complications were observed 48 hours after surgery in different anesthetic procedures. This prospective cross sectional study was carried out over a 12-month period. All subjects over 55 years of age undergoing hip fracture surgery were selected for study with ASA class (American Society of Anesthesiology: one, two and three). After determining the vital signs in the operating room, anesthesia type (general, spinal and epidural) and various variables were recorded. It was observed that the spinal anesthesia method had the lowest level of postoperative disturbances of consciousness and had the shortest duration in terms of duration of time. On the other hand, general anesthesia was the least in terms of blood transfusion. Finally, epidural anesthetic method showed the least amount of pain 48 hours after operation and the least changes in blood pressure and heart rate.
\end{abstract}

Key Words: Hip fracture, general anesthesia, neuraxial anesthesia.

Eur J Transl Myol 28 (3): 280-287, 2018

Hip fracture in the elderly is a very common fracture, which mainly requires surgical treatment ${ }^{1}$. This fracture is associated with various morbidity and mortality ${ }^{2}$. Agerelated hip fractures in the world are likely to be dependent on industrialization and decreased individual activity. ${ }^{3}$ Hip fracture (in upper part of the femur) is the major cause of mortality and morbidity in elderly people. ${ }^{4}$ It is estimated that between $10-20 \%$ of patients with hip fracture die in the first year, and two thirds of those who survive are also disabled. In Asia, the prevalence of osteoporosis is rapidly becoming a major health problem, which increases the incidence of hip fractures ${ }^{5}$. In 1990, about $30 \%$ of all osteoporosisinduced hip fractures occurred in Asia. It is estimated that this number will reach more than $50 \%$ by 2050 . The total number of hip fractures in Asia is estimated at 3.2 million cases per year ${ }^{6}$. In most populations, the incidence of hip fractures progressively increases with age ${ }^{7}$. Surgery for hip fracture is performed using either general anesthetic administration or neuraxial (spinal and epidural) method $^{8}$. Under general anesthesia, the patient becomes completely anesthetized by using injectable drugs or certain respiratory gases. In this method, the patient does not have the ability to breathe during anesthesia and the artificial respiratory machine is used to breathe. Neuraxial anesthesia (NA) is a type of anesthesia in which injection of anesthetic medication is an epidural or spinal administration. This procedure has very little side effect but cannot be performed in all types of surgical procedures, but cannot be used in hip replacement surgery ${ }^{9}$. In an epidural anesthesia, an anesthetic drug is injected into the patient's spine and along the nerves that come out of the spinal cord. The advantage of this method is to reduce bleeding during surgery. In this method, the likelihood of blood clotting in the lower extremities, which is a serious complication after surgery, is less than the general anesthesia. Postoperative headache and difficulty in urinating in the first few days after surgery can be a potential problem using this method ${ }^{10}$. Several studies have been done on the advantages and disadvantages of these methods ${ }^{11}$. Some studies have shown less complications of neuraxial approaches such as deep vein thrombosis (DVT), myocardial infarction and hypoxia. On the other hand, studies have shown that general anesthesia is associated with less cardiovascular complications and shorter surgical procedures ${ }^{12-16}$. In this study, various complications after hip fracture were investigated in different anesthetic procedures and 
Hip fracture surgery

Eur J Transl Myol 28 (3): 280-287, 2018

Table 1. Average duration of hip fracture surgery based on type of anesthesia

\begin{tabular}{ccccc}
\hline Type of anesthesia & $\begin{array}{c}\text { Average length of } \\
\text { operation }\end{array}$ & Standard deviation & Less time & Most time \\
\hline Spinal cord & 39.88 & 21.94 & 30 & 180 \\
General & 67.33 & 51.45 & 40 & 180 \\
Epidural & 70.92 & 41.96 & 25 & 150 \\
Total & 54.25 & 38.14 & 25 & 180 \\
\hline
\end{tabular}

$* * * * * * * * * * * * * * * * * * * * * * * * * * * * * * * * * * * * * * * * * * * * *$

Table 2. Frequency of blood transfusion during hip fracture surgery based on type of anesthesia

\begin{tabular}{cccc}
\hline Type of anesthesia & \multicolumn{2}{c}{ Frequency of blood intake } & Total \\
\cline { 2 - 3 } Spinal cord & have received & Have not received & 89 \\
& 25 & $\% 71.92$ & $\% 100$ \\
General & $\% 28.08$ & 18 & 30 \\
& 12 & $\% 60$ & 52 \\
Epidural & $\% 40$ & 31 & $\% 100$ \\
& 21 & $\% 59.62$ & 171 \\
Total & $\% 40.38$ & 113 & $\% 100$ \\
\hline
\end{tabular}

compared with each other. If it is determined which anesthetic method is associated with less stress during the surgery for the age group $>55$ years, this method can be recommended in patients who need anesthesia. In this prospective cross-sectional study, all patients undergoing general anesthesia or neuraxial anesthesia are evaluated for the frequency of complications during and after hip surgery for up to 48 hours.

\section{Materials and Methods}

This prospective cross-sectional study was conducted over a 12-month period. The population studied was all people over the age of 55 who needed surgical treatment due to hip fractures and had to undergo anesthesia. The sample size was selected by census method for estimating related observations. Patients over the age of 55 with ASA class 1, 2 and 3 were candidates for hip fracture surgery in Vali-e-Asr Hospital of Arak, Iran. Patient exclusion criteria included an allergic reaction to a blood transfusion, severe cement reaction, a very long surgery, changes in surgical plan during operation, and lack of patient collaboration and patient satisfaction. All patients were followed up prior to surgery, where $\mathrm{Hb}$ and systemic blood pressure (systolic and diastolic), BMI, age, sex, history of underlying disorders, and class (ASA) and inclusion criteria were recorded in the checklist.
Moreover, in the operating room after the registration of vital signs, the type of anesthesia (general, spinal and epidural) was recorded. General anesthesia involves three different methods, and the medications and procedures used were also written in the checklist for each patient. The researcher was the only observer of the anesthetic method and anesthesia was performed by anesthesiology team at Vali-e-Asr Hospital in Arak.

The variables examined are as follow: 1. Type of anesthesia, 2. Drugs and the type of needle and catheter, 3. Amount of prescribing fluid during the operation, 4. In case of hypotension, ttype and amount of prescribed medications, 5. Amount of blood lost during the operation based on the number of gas and liquefied natural gas (LNG) consumed (each fully wet gas is $10 \mathrm{cc}$ and LNG $50 \mathrm{cc}$ ), 6. Amount of blood in the suction, 7. Amount of injected blood during surgery, 8. Time of surgery (the onset of anesthesia or numbness before the end of the surgery), 9. Amount of $\mathrm{Hb}$ before and 6 hours after the operation, 24 and 48 hours later, 10. Severity of pain, which was assigned using a VAS ruler (0 to 10) at end of recovery, and 6 hours, 24 hours and 48 hours after operation, 1. Dose of opioid and injecting painkillers were divided in 6, 24, 48 hours after operation, and total amount of opiate and painkillers used, 12. Awareness of 
Hip fracture surgery

Eur J Transl Myol 28 (3): 280-287, 2018

Table 3. Hemoglobin value before, 6, 24 and 48 hours after hip fracture according to type of anesthesia

\begin{tabular}{|c|c|c|c|c|c|}
\hline \multicolumn{2}{|c|}{ Type of anesthesia } & \multirow{2}{*}{$\begin{array}{c}\begin{array}{c}\text { Hemoglobin } \\
\text { before surgery }\end{array} \\
13.34\end{array}$} & \multirow{2}{*}{$\begin{array}{c}\begin{array}{c}\text { Hemoglobin } 6 \\
\text { hours later }\end{array} \\
11.89\end{array}$} & \multirow{2}{*}{$\begin{array}{c}\text { Hemoglobin } 24 \\
\text { hours later }\end{array}$} & \multirow{2}{*}{$\begin{array}{c}\begin{array}{c}\text { Hemoglobin } 48 \\
\text { hours later }\end{array} \\
11.59\end{array}$} \\
\hline Spinal & HB Average & & & & \\
\hline cord & $\begin{array}{l}\text { Standard } \\
\text { deviation }\end{array}$ & 1.91 & 2.52 & 2.48 & 1.26 \\
\hline \multirow{6}{*}{ general } & Least & 10.70 & 7.70 & 7.90 & 8.90 \\
\hline & the most & 16.90 & 17.80 & 18.50 & 13.60 \\
\hline & HB Average & 12.74 & 11.86 & 11.30 & 11.56 \\
\hline & $\begin{array}{l}\text { Standard } \\
\text { deviation }\end{array}$ & 1.92 & 1.26 & 1.61 & 2.10 \\
\hline & Least & 10.80 & 10.80 & 9.80 & 8.30 \\
\hline & the most & 15.90 & 14.20 & 14.30 & 14.80 \\
\hline \multirow[t]{4}{*}{ Epidural } & HB Average & 12.37 & 11.12 & 10.28 & 11.28 \\
\hline & $\begin{array}{l}\text { Standard } \\
\text { deviation }\end{array}$ & 2.00 & 1.77 & 2.20 & 1.86 \\
\hline & Least & 10.40 & 8.90 & 6.70 & 8.70 \\
\hline & the most & 15.90 & 14.90 & 13.30 & 14.00 \\
\hline \multirow[t]{4}{*}{ total } & HB Average & 12.94 & 11.64 & 11.04 & 11.49 \\
\hline & $\begin{array}{l}\text { Standard } \\
\text { deviation }\end{array}$ & 1.98 & 2.15 & 2.31 & 1.62 \\
\hline & Least & 10.40 & 7.70 & 6.70 & 8.30 \\
\hline & the most & 16.90 & 17.80 & 18.50 & 14.80 \\
\hline
\end{tabular}

time, place and person (cognitive function) at end of recovery, and 6, 24 and 48 hours after surgery.

Regarding the importance of the underlying disease in choosing anesthetic method, they were provided in a checklist for each patient. Moreover, postoperative complications such as DVT, CHF and MI, atelectasis, lung infection, urinary tract infection, wound infection and sepsis, CVA, and death were reported during 48 hours. Furthermore, the duration of admission after the operation was followed and recorded. Statistical analysis of patients was performed according to the age group of 55 to 65,65 to 75 and above 75 , as well as based on ASA class in 3 groups. Gender factor was also considered for all variables. Data were entered into SPSS 21 software and then analyzed. Furthermore, chi-square test and independent samples T-test were used for quantitative data. This study was approved by the Ethics Committee of the Arak Medical University.

\section{Results and Discussion}

This study was performed on 171 patients ( 65 female and 106 male) over 55 years of age undergoing hip fracture surgery at Vali-e-Asr Hospital in Arak. As to their age, 35 patients were 55 to 65 years old, 30 were $66-75$ years old, 54 were 76-85 years old, and 46 patients were 86-95 years old. Spinal anesthesia was also used for 89 patients (52\%), general anesthesia was used for 30 patients $(17.5 \%)$ and epidural anesthesia was used for 46 patients (26.9\%). Spinal anesthesia was used for 30 female and
59 male patients. As to BMI of patients undergoing hip fracture surgery, 41 patients had BMI of 23, 36 patients of 24,41 patients of 25 and 53 patients of 26 . The average length of the operation in all three types of anesthesia was 54.25 minutes with a standard deviation of 38.14. The shortest operating time was 25 minutes in an epidural anesthetic type. The longest operating time was 180 minutes, which was recorded for spinal anesthesia and general anesthesia (Table 1). In all three groups 58 patients $(33.91 \%)$ received blood and 113 patients $(66.08 \%)$ did not receive blood (Table 2). Calculating the amount of HB before, 6, 24 and 48 hours after the hip fracture operation showed that the mean of total hemoglobin before surgery in all three types of anesthesia was determined to be 12.94 with a standard deviation of 1.98, while the mean of hemoglobin values 48 hours after surgery was achieved as 11.49 and the standard deviation was calculated to be 1.62 (Table 3 ). Table 4 shows the mean postoperative pain intensity during recovery $(6,24$ and 48 hours after hip fracture) based on type of anesthesia. The average pain intensity during the last 6 hours after surgery in all three types of anesthesia was 5.00 with a standard deviation of 1.39 . The average dose of the analgesic 6 hours after the operation in all three types of anesthesia was $6.64+/-5.22$ SD (Table 5). Changes in blood pressure after hip fracture surgery according to the type of anesthesia showed that in all three methods, 55 patients $(32.16 \%)$ had hypotension, whereas 44 patients $(25.73 \%)$ showed hypertension after 
Table 4. Average pain intensity after surgery in recovery, 6, 24 and 48 hours after hip fracture operation according to type of anesthesia

\begin{tabular}{|c|c|c|c|c|}
\hline \multicolumn{2}{|c|}{ Type of anesthesia } & \multirow{2}{*}{$\begin{array}{c}\text { Pain level } 6 \text { hours } \\
\text { after surgery }\end{array}$} & \multirow{2}{*}{$\begin{array}{c}\text { Pain level } 24 \text { hours } \\
\text { after surgery }\end{array}$} & \multirow{2}{*}{$\begin{array}{c}\text { Pain level } 48 \text { hours } \\
\text { after surgery }\end{array}$} \\
\hline Spinal cord & Average pain & & & \\
\hline & $\begin{array}{l}\text { Standard } \\
\text { deviation }\end{array}$ & 1.29 & 1.22 & 1.22 \\
\hline & the most & 3 & 2 & 0 \\
\hline & Least & 8 & 6 & 4 \\
\hline \multirow[t]{4}{*}{ general } & Average pain & 6.80 & 4.80 & 2.80 \\
\hline & $\begin{array}{l}\text { Standard } \\
\text { deviation }\end{array}$ & 0.99 & 0.99 & 0.99 \\
\hline & the most & 6 & 4 & 2 \\
\hline & Least & 8 & 6 & 4 \\
\hline \multirow[t]{4}{*}{ Epidural } & Average pain & 4.44 & 2.22 & 0.55 \\
\hline & $\begin{array}{l}\text { Standard } \\
\text { deviation }\end{array}$ & 0.83 & 0.63 & 1.07 \\
\hline & the most & 4 & 2 & 0 \\
\hline & Least & 6 & 4 & 3 \\
\hline \multirow[t]{4}{*}{ total } & Average pain & 5.00 & 2.96 & 1.06 \\
\hline & $\begin{array}{l}\text { Standard } \\
\text { deviation }\end{array}$ & 1.39 & 1.35 & 1.39 \\
\hline & the most & 3 & 2 & 0 \\
\hline & Least & 8 & 6 & 4 \\
\hline
\end{tabular}

the operation (Table 6). Patients undergoing spinal anesthesia were affected by 2 deaths $(2.24 \%)$. Mortality rate was $13.33 \%$ (4 patients) in patients undergoing general anesthesia. No mortality was recorded in patients undergoing epidural anesthesia. The hip fracture is very common in the elderly and usually requires surgical treatment, which in most cases is associated with a high incidence of complications. ${ }^{1}$ The current study aimed to compare the short-term complications of anesthetic procedures used in hip fracture surgery in the elderly, in which various variables were measured. It has been observed that hemoglobin levels in people with pelvic bone fracture severely decrease. This causes the person to sustainably develop bleeding and anemia after the fracture. Previous studies have shown that low levels of hemoglobin in patients lead to poor prognosis. ${ }^{17-21}$ However, we still do not have accurate information on bleeding and hemoglobin levels in a variety of fractures. In this study, the mean of hemoglobin in patients who underwent spinal anesthesia before surgery was determined to be higher (13.34), followed by the group under general anesthesia (12.74) and the group under epidural anesthesia (12.37). The mean hemoglobin of patients 6 hours after operation under spinal anesthesia was 11.89 , while determined as $11.86,6$ hours after operation under general anesthesia and 11.12, 6 hours after surgery under epidural anesthesia. According to the results, the mean hemoglobin of patients was recorded at the rate of 11.4024 hours after operation. While this rate was determined as 11.30 and 10.28, 24 hours after operation under general anesthesia and epidural anesthesia, respectively. It was also determined to be 11.5948 hours after operation under spinal anesthesia, 11.56 under general anesthesia and 11.28 under epidural anesthesia. It was observed that the highest mean hemoglobin drop in the group under spinal anesthesia occurred 6 hours after operation while after 24 hours; the highest mean hemoglobin drop was in the group under general anesthesia, as well as after 48 hours in the group under spinal anesthesia. Heidari et al. compared two methods of general anesthesia (GA) and anesthesia (NA) in pelvic fracture patients. The mean of hemoglobin before surgery in both groups was 12.4 , which decreased by 1.4 after the operation in the following days in both groups. ${ }^{1}$ In the present study, the average hemoglobin concentration was approximately equal in all groups after 48 hours. Rosencher et al, observed that bloodletting should be initiated if the hemoglobin level reaches 8.93 $\pm 1.83 .{ }^{22}$ Another study found that $45.6 \%$ of patients with pelvic fracture were anemic. ${ }^{23}$ Long-term surgery is a known risk factor for surgical infections, which is the cause of hospital infections and high mortality in patients. It also plays a major role in pelvic and knee surgery. ${ }^{23-25}$ In the present study, the average length of operation in spinal anesthesia was 39.88 minutes, but it reached to 67.33 and 70.92 minutes in the general and epidural anesthesia, respectively. Parker et al. found that the duration of the operation was 187 minutes in general anesthesia and 189 minutes in regional anesthesia (189 minutes). In another study, the duration of surgery in 
Table 5. Analgesic consumption dose at 6, 24 and 48 hours after hip fracture operation according to type of anesthesia

\begin{tabular}{|c|c|c|c|c|}
\hline \multicolumn{2}{|c|}{ Type of anesthesia } & \multirow{2}{*}{$\begin{array}{c}\text { The dosage of } \\
\text { consumable } \\
\text { medication is } 48 \\
\text { hours after surgery } \\
5.55\end{array}$} & \multirow{2}{*}{$\begin{array}{c}\text { The dosage of } \\
\text { consumable } \\
\text { medication is } 48 \\
\text { hours after surgery } \\
5.04\end{array}$} & \multirow{2}{*}{$\begin{array}{c}\text { The dosage of } \\
\text { consumable } \\
\text { medication is } 48 \\
\text { hours after surgery } \\
6.95\end{array}$} \\
\hline Spinal cord & $\begin{array}{l}\text { Average housing } \\
\text { dose }\end{array}$ & & & \\
\hline & Standard deviation & 4.32 & 3.62 & 5.19 \\
\hline & Least & 0.0 & 0.0 & 0.0 \\
\hline & the most & 14 & 14 & 18 \\
\hline \multirow[t]{4}{*}{ general } & $\begin{array}{l}\text { Average housing } \\
\text { dose }\end{array}$ & 8.40 & 8.40 & 8.40 \\
\hline & Standard deviation & 6.85 & 6.85 & 6.85 \\
\hline & Least & 1 & 1 & 1 \\
\hline & the most & 21 & 21 & 21 \\
\hline \multirow[t]{4}{*}{ Epidural } & $\begin{array}{l}\text { Average housing } \\
\text { dose }\end{array}$ & 7.44 & 10.66 & 9.66 \\
\hline & Standard deviation & 5.21 & 5.92 & 5.98 \\
\hline & Least & 3 & 3 & 3 \\
\hline & the most & 19 & 19 & 19 \\
\hline \multirow[t]{4}{*}{ total } & $\begin{array}{l}\text { Average housing } \\
\text { dose }\end{array}$ & 6.64 & 7.40 & 8.07 \\
\hline & Standard deviation & 5.22 & 5.65 & 5.85 \\
\hline & Least & 0.0 & 0.0 & 0.0 \\
\hline & the most & 21 & 21 & 21 \\
\hline
\end{tabular}

anesthesia was shorter than the duration of anesthesia surgery (55.81 minutes versus 65.36 minutes). ${ }^{9}$ In the present study, the duration of operation in the spinal cord was less than the general method. Blood transfusions are usually performed for patients who have lost a lot of blood. This action is also done in many patients with pelvic fracture. However, blood transfusions to the patient create many problems, including high risk of transmission of infections including AIDS, hepatitis, etc., or even other problems such as fever, increased hemodynamic load, etc. ${ }^{26-27}$. In the present study, it was found that $28.08 \%$ of patients who had spinal anesthesia had a need for blood transfusion, while $40 \%$ of patients who had undergone general anesthesia needed blood transfusions. Moreover, $40.38 \%$ of patients who had an epidural anesthetic required blood transfusions. Another study reported that patients with general anesthesia received $100 \mathrm{ml}$ of blood and $103 \mathrm{ml}$ of blood was injected for patients with regional anesthetics. ${ }^{11}$ Another study also found that $39.34 \%$ of those who received spinal anesthesia needed blood transfusions, while $45.49 \%$ of patients needed blood transfusions for patients taking general anesthesia. ${ }^{15}$ Our findings also revealed that the need for blood transfusion in patients who received general anesthesia was more than those who used spinal anesthesia. Postoperative pain is one of the major problems suffered by patients after surgery and requires strong painkillers to relieve pain. It has been shown in studies that postoperative pain sensation has a direct linear relationship with anxiety status. ${ }^{28}$ In the current study, the mean pain score 6 hours after operation in the spinal anesthesia group was $4.73+/-1.29$ (SD), while the mean pain sensation score at the same time in the general anesthesia group was $6.80+/-0.99$ (SD). Mean pain score for the epidural group at the same time was $4.44+/-0.83$ (SD). Robert et al. compared the pain sensation after lumbar plexus block with general anesthesia method in patients undergoing hip arthroplasty. They indicated that pain scores remained lower in the plexus group until $6 \mathrm{~h}$ after randomization $1.4+/-1.3$ vs. $2.4+/-1.4$ (SD). ${ }^{29}$ The mortality rate of patients after surgery is one of the most important unpleasant events that can be very painful for their families. In the current study, mortality rate after hip fracture surgery in a group of patients with spinal anesthesia was $2.24 \%$, while the general anesthesia group showed $13.33 \%$ mortality and the spinal anesthesia group did not show any deaths. Rodgers et al. found that mortality rates in patients who used neuraxial anesthesia including spinal and epidural were $2.11 \%$ and $3.07 \%$ for patients who did not use this method. ${ }^{30}$ Our study also found that mortality rates were higher in the group 
Hip fracture surgery

Eur J Transl Myol 28 (3): 280-287, 2018

Table 6. Blood pressure changes after hip surgery according to the type of anesthesia

\begin{tabular}{ccccc}
\hline Type of anesthesia & \multicolumn{3}{c}{ Type of anesthesia } & total \\
\cline { 2 - 3 } Spinal cord & 29 & $\begin{array}{c}\text { Low blood pressure } \\
\text { unchanged }\end{array}$ & $\begin{array}{c}\text { Increased blood } \\
\text { pressure }\end{array}$ & \\
& & 37 & 23 & 89 \\
general & $\% 32.58$ & $\% 41.57$ & $\% 25.84$ & $\% 100$ \\
& 11 & 9 & 10 & 30 \\
Epidural & $\% 36.66$ & $\% 30$ & $\% 33.33$ & $\% 100$ \\
& 15 & 26 & 11 & 52 \\
total & $28.84 \%$ & $\% 50$ & $\% 21.15$ & $\% 100$ \\
& 55 & 72 & 44 & 171 \\
& $\% 32.16$ & $\% 42.10$ & $\% 25.73$ & $\% 100$ \\
\hline
\end{tabular}

receiving general anesthesia. Deep vein thrombosis (DVT) is one of the most important problems that affect 2.5 to 5 percent of people throughout their lives. Its major short-term complication is pulmonary embolism and its major long-term complication is the post-thrombotic syndrome (PTS). ${ }^{31,32}$ In the present study, the incidence of deep vein thrombosis in the spinal anesthesia group was $11.23 \%$, while $6.66 \%$ for general anesthesia group and $5.76 \%$ for epidural anesthetic group. Modig reported that the incidence of deep vein thrombosis in patients with epidural anesthesia was less than that of the general anesthesia group. ${ }^{33}$ In the present study, it was also observed that the mortality rate in the group with epidural anesthesia was lower than in other groups. With regard to the results and complications of each type of anesthetic method, the appropriate approach should be chosen according to the patients. For patients with heart problems, for example, epidural anesthesia is better because of lower blood pressure and heart rate changes. Furthermore, general anesthesia is worse in these patients because it often causes changes in blood pressure and heart rate. In conclusion, it is suggested that this study be repeated in other centers, with a higher population in order to achieve more conclusive results.

\section{List of acronyms}

ASA - American Society of Anesthesiology

DVT - Deep vein thrombosis

LNG - liquefied natural gas

GA - General Anesthesia

NA - Neuraxial anesthesia

PTS - Post-thrombotic syndrome

SD - Standard Deviation

\section{Author's contributions}

Each author contributed in equal part to the manuscript.

\section{Acknowledgments}

This article is a result of Ms. Fuzhan Behrouzzadeh's thesis for obtaining a doctorate from Arak University of Medical Sciences.

Funding: None.

\section{Conflict of Interest}

The authors declare no conflicts of interests.

\section{Ethical Publication Statement}

We confirm that we have read the Journal's position on issues involved in ethical publication and affirm that this report is consistent with those guidelines.

\section{Corresponding Author}

Alireza Kamali, Department of Anesthesiology, Arak University of Medical Sciences, Arak, Iran. Phone: 00989181622810 Email: alikamaliir@yahoo.com

\section{E-mail of co-authors}

Afsaneh Norouzi: norouzi.a@arakmu.ac.ir

Fozhan Behrouzibakhsh: fozhanbehrouzibakhsh@yahoo.com

Bijan Yazdi: yazdi@arakmu.ac.ir

Babak Ghaffari: babakghaffari@gmail.com

\section{References}

1. Cumming RG, Nevitt MC, Cummings SR. Epidemiology of hip fractures. Epidemiol Rev 1997;19:244-57.

2. Heidari SM, Soltani H, Hashemi SJ, et al. Comparative study of two anesthesia methods according to postoperative complications and one month mortality rate in the candidates of hip surgery. J res med sci 2011;16:323-30. 
3. Kannus P, Parkkari J, Sievänen H, Heinonen A, Vuori I, Järvinen M. Epidemiology of hip fractures. Bone 1996;18:S57-S63.

4. Gdalevich M, Cohen D, Yosef D, Tauber C. Morbidity and mortality after hip fracture: the impact of operative delay. Arch orthop trauma surg 2004;124:334-40.

5. Lau E, Woo J. Osteoporosis in Asia. Nutrition and Osteoporosis: Springer; 1994 :101-18.

6. Urwin S, Parker M, Griffiths R. General versus regional anaesthesia for hip fracture surgery: a meta-analysis of randomized trials. $\mathrm{Br} \mathrm{j}$ anaesth 2000;84:450-5.

7. Kenzora JE, Mccarthy RE, J Drennan L, Sledge CB. Hip fracture mortality: relation to age, treatment, preoperative illness, time of surgery, and complications. Clinical orthopaedics and related research 1984;186:45-56.

8. Frank SM, Beattie C, Christopherson R, et al. Epiduralversus general anesthesia, ambient operating room temperature, and patient age as predictors of inadvertent hypothermia. Anesthesiology 1992;77:252-7.

9. Fredrickson M, Kilfoyle D. Neurological complication analysis of 1000 ultrasound guided peripheral nerve blocks for elective orthopaedic surgery: a prospective study. Anaesthesia 2009;64:836-44.

10. Absalom AR, Sutcliffe N, Kenny GN. Closedloop Control of Anesthesia Using Bispectral IndexPerformance Assessment in Patients Undergoing Major Orthopedic Surgery under Combined General and Regional Anesthesia. Anesthesiology 2002;96:67-73.

11. Basques B, Bohl D, Golinvaux N, Samuel A, Grauer J. General versus spinal anaesthesia for patients aged 70 years and older with a fracture of the hip. Bone Joint J 2015;97:689-95.

12. Parker MJ, Handoll HH, Griffiths R. Anaesthesia for hip fracture surgery in adults. The Cochrane Library 2004.

13. Luger T, Kammerlander C, Gosch M, et al. Neuroaxial versus general anaesthesia in geriatric patients for hip fracture surgery: does it matter? Osteoporos int 2010;21:555-72.

14. Basques BA, Toy JO, Bohl DD, Golinvaux NS, Grauer JN. General compared with spinal anesthesia for total hip arthroplasty. J Bone Joint Surg Am 2015;97:455-61.

15. Helwani MA, Avidan MS, Abdallah AB, et al. Effects of regional versus general anesthesia on outcomes after total hip arthroplasty. J Bone Joint Surg Am 2015;97:186-93.

16. Fields AC, Dieterich JD, Buterbaugh $\mathrm{K}$, Moucha CS. Short-term complications in hip fracture surgery using spinal versus general anaesthesia. Injury 2015;46:719-23.
17. Wu JZ, Liu PC, Ge W, Cai M. A prospective study about the preoperative total blood loss in older people with hip fracture. Clin Interv Aging 2016;11:1539.

18. Khan MA, Hossain FS, Ahmed I, et al. Predictors of early mortality after hip fracture surgery. Int orthop 2013;37:2119-24.

19. Bhaskar D, Parker MJ. Haematological indices as surrogate markers of factors affecting mortality after hip fracture. Injury 2011;42:17882.

20. Vochteloo AJ, van der Burg BL, Mertens BJ, et al. Outcome in hip fracture patients related to anemia at admission and allogeneic blood transfusion: an analysis of 1262 surgically treated patients. BMC musculoskelet disord 2011;12:262.

21. Foss NB, Kristensen MT, Kehlet H. Anaemia impedes functional mobility after hip fracture surgery. Age ageing 2008;37:173-8.

22. Rosencher N, Kerkkamp HE, Macheras G, et al. Orthopedic Surgery Transfusion Hemoglobin European Overview (OSTHEO) study: blood management in elective knee and hip arthroplasty in Europe. Transfusion 2003;43:459-69.

23. Gruson KI, Aharonoff GB, Egol KA, et al. The relationship between admission hemoglobin level and outcome after hip fracture. J orthop trauma 2002;16:39-44.

24. Dicks KV, Baker AW, Durkin MJ, et al. Short operative duration and surgical site infection risk in hip and knee arthroplasty procedures. Infect control hosp epidemiol 2015;36:1431-6.

25. Magill SS, Edwards JR, Bamberg W, et al. Multistate point-prevalence survey of health care-associated infections. New Engl J Med 2014;370:1198-208.

26. Mangram AJ, Horan TC, Pearson ML, et al. Hospital Infection Control Practices Advisory Committee. Guideline for prevention of surgical site infection, 1999. Am j infect control. 1999;27:97-134.

27. Salido JA, Marín LA, Gómez LA, Zorrilla P, Martínez C. Preoperative hemoglobin levels and the need for transfusion after prosthetic hip and knee surgery. J Bone Joint Surg Am 2002;84:216-20.

28. Bierbaum BE, Callaghan JJ, Galante JO, et al. An analysis of blood management in patients having a total hip or knee arthroplasty. J Bone Joint Surg Am 1999;81:2-10.

29. Mitchell RW, Smith G. The control of acute postoperative pain. Br J Anaesth 1989;63:14758.

30. Stevens RD, Van Gessel E, Flory N, et al. Lumbar plexus block reduces pain and blood 


\section{Hip fracture surgery}

Eur J Transl Myol 28 (3): 280-287, 2018

loss associated with total hip arthroplasty. Anesthesiology 2000;93:115-21.

31. Rodgers A, Walker N, Schug S, et al. Reduction of postoperative mortality and morbidity with epidural or spinal anaesthesia: results from overview of randomised trials. Bmj 2000;321:1493.

32. Watson L, Broderick C, Armon MP. Thrombolysis for acute deep vein thrombosis. The Cochrane Library 2014 Jan 1.
33. Modig J, Borg T, Karlström G, et al. Thromboembolism after total hip replacement: role of epidural and general anesthesia. Anesth Analg 1983;62:174-80.

Submission: February 17, 2018

Revision received: February 22, 2018

Acceptance: February 23, 2018 